\title{
Does satiation close the open economy?
}

\author{
DIANA POSADAS-SÁNCHEZ and PETER R. KILLEEN \\ Arizona State University, Tempe, Arizona
}

\begin{abstract}
Pigeons responded on fixed-interval and fixed-ratio food schedules during sessions of extended duration. Pause lengths from the beginning of the session, when the subjects were hungry, resembled those found in open economies, whereas pause lengths from the end of the sessions, when the subjects were close to satiation, resembled those from closed economies. A model of motivation captured key features of the data, suggesting that a changing level of hunger is a causal factor in the behavioral differences observed between open and closed economies. Behavioral theories may provide a parsimonious alternative to economic theories in accounting for such effects.
\end{abstract}

The last quarter of the 20th century saw a significant departure from the standard operant experimental paradigm in which subjects work under conditions of food deprivation designed to maintain relatively constant high motivation. The new paradigms permitted animals to work under conditions approaching ad lib access to significant reinforcers, which may more closely approximate the cycle of depletion and repletion found in the natural environment. The resulting data provided an opportunity to apply novel analytic techniques, such as microeconomic theory. Lea (1978) has carefully examined similarities between economic and behavioral frameworks. Reinforcers are prototypic economic commodities-goods. A schedule requirement is somewhat like a price, and a graph of the number of reinforcers taken as a function of price provides an analogue of the economist's demand function. The traditional operant paradigm is classified as an open economy, because food and water are usually provided after the session, fitting the classic definition of an open economy - that is, one in which services and funds flow freely in and out, with no import quotas, export restrictions, or exchange controls. Experimental paradigms in which subjects live in the experimental chamber continuously — such as Logan's (1964) free-behavior paradigm or Bernstein and Ebbesen's (1978) economic environments-resemble closed economies, defined as markets that do not trade with the rest of the world. It is the study of experimentally closed economies that has generated recent interest.

In traditional (open) experiments, subjects are maintained at a relatively constant, relatively high level of deprivation, with experimental sessions lasting approxi-

This research was presented at the 28th Annual Convention of the Association for Behavior Analysis, Toronto, 2002. It was supported by NSF Grant IBN 0236821 and NIMH Grant 1R01MH066860. We thank Lauren C. Kettle and Mark R. Blair for excellent technical assistance. Correspondence concerning this article should be addressed to D. PosadasSánchez or P. R. Killeen, Department of Psychology, Arizona State University, Box 871104, Tempe, AZ 85287-1104 (e-mail: posadas@asu .edu or killeen@asu.edu). mately an hour. In other (closed) experiments, larger reinforcers - often, extended bouts of consumption - are employed, and sessions are often significantly longer. Deprivation levels vary as a function of the subject's ability to replete the calories lost in the interval between consummatory bouts. The distinctions between these paradigms depend on the author. Collier and Johnson (e.g., Collier \& Johnson, 1990; Collier, Johnson, Hill, \& Kaufman, 1986; Johnson \& Collier, 1999) call the traditional experiments a "refinement" paradigm, and contrast it with paradigms in which the subjects are able to satiate at each feeding (although the time between feedings is under joint control of the subject and the experimenter). Hall and Lattal (1990) distinguish experiments in which the body weight of the subject is perfectly correlated with its experimental behavior (closed) or imperfectly correlated (because of postsession feeding; open), a distinction similar to Hursh's (1984), who cites an imperfect correlation between behavior within the session and overall food intake as a defining characteristic of open economies.

Qualitatively different patterns of behavior may occur in open and closed economies, whether the experiment involves timing (e.g., Zeiler, 1991) or basic schedule effects. Hursh (1978) demonstrated that in closed economies, monkeys' response rates and time allocations were inversely related to the rate of food presentation. This was consistent with the inverse relationship between magnitude of reinforcement and rate of responding found in other closed economies (e.g., Collier, Hirsch, \& Hamlin, 1972) but is contrary to the traditional results with subjects maintained at constant low body weights. In such open economies, animals respond more quickly for better (larger, more frequent) goods, whereas in closed economies animals respond more slowly for better goods.

What causes these differences? Along with the operational distinctions between open and closed economies, mentioned above, come a host of other differences in the way such experiments are conducted. (1) Meal sizes are often larger in closed economies. (2) Session lengths are often longer in closed economies. (3) Body weights are typically closer to ad lib weights in closed than in open 
economies. Which among this constellation of differences matter? Session length may not be a factor: Hall and Lattal (1990) reported the now standard differences in behavior patterns in closed economies that lasted for only an hour and open economies that involved no postsession feeding (which, by some definitions, makes them closed; cf. Foster, Blackman, \& Temple, 1997).

Is commodity substitution based on anticipation of future reward the cause of the differences? In an open economy, subjects might anticipate access to the low-cost supplemental feeding following the session, causing demand for reward within the session to be more elastic. As reward density decreases within the session, the subject may increasingly postpone intake until the session ends and the less costly reward becomes available. But explanation in terms of deferred consumption assumes foresight, planning, and some measure of self-control on the part of animals that fail to show even modest selfcontrol over delays of dozens of seconds. Timberlake (1984) found that responding at high ratios in progressiveratio schedules was not reduced by free food given an hour after the session. Timberlake, Gawley, and Lucas (1987) extended these results, showing that only when free food was available within $15 \mathrm{~min}$ of the end of the session was responding affected. The findings of Timberlake and associates rule out any important substitution effect due to supplemental feeding. Furthermore, Zeiler (1999), Hall and Lattal (1990), and others have demonstrated the standard differences between response patterns in open and closed economies under conditions of minimal postsession feeding.

Zeiler (1999) has provided a clear demonstration of the dramatically different patterns of behavior that can be obtained under open and closed economies. Zeiler (1999) used the same schedules of reinforcement in both paradigms. In the open economies, pigeons were maintained at $80 \%$ of their ad lib weights, and the sessions ended after 30 feeder cycles or $24 \mathrm{~h}$, whichever came first. If the bird's weight fell below $80 \%$ of its ad lib weight for three consecutive sessions, the duration was increased at the start of the next session to prevent it from losing weight. Supplemental feeding was also provided at the end of each session. In his closed economies, pigeons lived in operant chambers $24 \mathrm{~h}$ a day and pecked a key for their food without extrinsic deprivation. Response rates were maintained at fixed ratios (FRs) ranging up to 10,000 - much larger than those attainable in open economies of short duration. More important, pause lengths and response rates changed in different ways as a function of schedule demands in the two conditions (see the first column in Figure 1). The primary purpose of our study is to reexamine these findings, seeking a causal basis for these differences.

We modified Zeiler's (1999) procedure by using a single long session in which pigeons started hungry. The subjects were exposed to series of fixed-interval (FI) or FR schedules for two sessions at each interval or ratio value, with 1 or 2 days between each session. Following Zeiler's (1999) procedure, the pigeons' pecking of the schedule key produced an opportunity to peck a second key to obtain reinforcers on a continuous reinforcement schedule. Experiments 1-2 afforded the pigeons differing amounts of food following schedule completion. Experiment 3 used FR schedules in place of the FI schedules. If differential motivation causes the different response patterns, the pigeons should demonstrate patterns typical of open economies at the start of sessions when they are hungry; by the end of the long sessions, when their crops are fuller (Bizo, Bogdanov, \& Killeen, 1998; Hopkins, 1966), they should demonstrate patterns more typical of closed economies. Alternatively, satiation may contribute little to the within-session decreases in the proposed experiments (Roll, McSweeney, Johnson, \& Weatherly, 1995). Instead, the animals may be habituating to the reinforcer (McSweeney, Hinson, \& Cannon, 1996; McSweeney, Roll, \& Weatherly, 1994; McSweeney \& Swindell, 1999). In either case, the predicted differences should hold in open (i.e., extra-session feeding) and closed economic environments.

\section{EXPERIMENT 1}

Experiment 1 assessed whether a transition from behavior patterns typical of open economies to those of closed economies could be obtained in a single session. Zeiler (1999) provided the reference paradigm and data.

\section{Method}

Subjects. Four experienced adult pigeons (Columba livia) served as subjects. The birds started the sessions at $85 \%$ of their free-feeding body weight. To attain this level of deprivation, it was necessary to conduct sessions on alternate days. All the pigeons were housed in individual cages, with water and grit freely available. No supplemental feeding was provided.

Apparatus. Two operant conditioning chambers for pigeons, measuring $31 \mathrm{~cm}$ wide $\times 35 \mathrm{~cm}$ deep (front panel) $\times 35 \mathrm{~cm}$ high, were used. Three response keys were mounted horizontally, $25 \mathrm{~cm}$ above the floor behind $2.5-\mathrm{cm}$ holes in the front wall. The keys were $8.5 \mathrm{~cm}$ apart, center to center, and could be transilluminated with colored lights. Only the right and left keys were used in the experiment. A minimum force of $0.15 \mathrm{~N}$ on the response keys registered as a response. A houselight was located above the center key, $3 \mathrm{~cm}$ below the ceiling. A rectangular hopper opening was centered $13 \mathrm{~cm}$ below the row of response keys. When the hopper was raised, it provided access to grain illuminated by a white light mounted in the top of the hopper opening. In the rear left corner of the chamber, a plastic container provided water during the session. Extraneous sounds were masked by white noise and by a ventilation fan in the chambers.

Procedure. The pre- and postsession weights for all the subjects were recorded. Each sequence began with the left white key (the schedule key) illuminated and the right green key (the food key) dark. The completion of the schedule requirement on the left key darkened that key and illuminated the food key. A single peck to the food key darkened it and resulted in a $2.5-\mathrm{sec}$ access to the food hopper. The food key was then reilluminated, and a single peck to it again darkened it and gave another 2.5 -sec access to the hopper. The pigeons obtained two accesses to the hopper per cycle, which emulated Zeiler's (1999) procedure, although he permitted the pigeons to continue responding on the food key until satiated. After this feeding cycle, the schedule key was illuminated, and the schedule began anew. Water was continuously available during the experimental session, which ended after $10 \mathrm{~h}$. All the sessions were followed by 1 fallow day (no food), to allow weights to drop back to $85 \%$ ad lib. At the longest intervals, where within-session repletion was incom- 
Zeiler (1999)
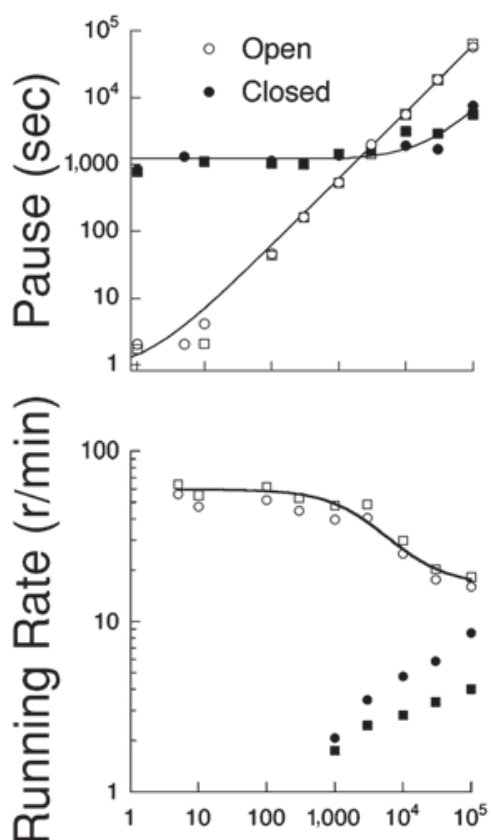

2 Hoppers/Cycle
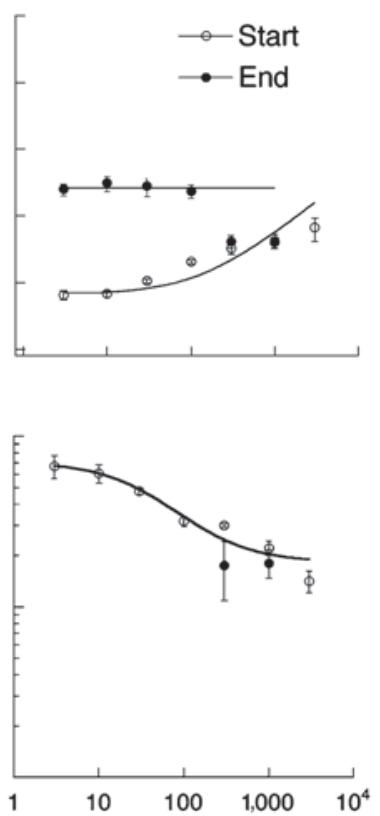

\section{Hoppers/Cycle}
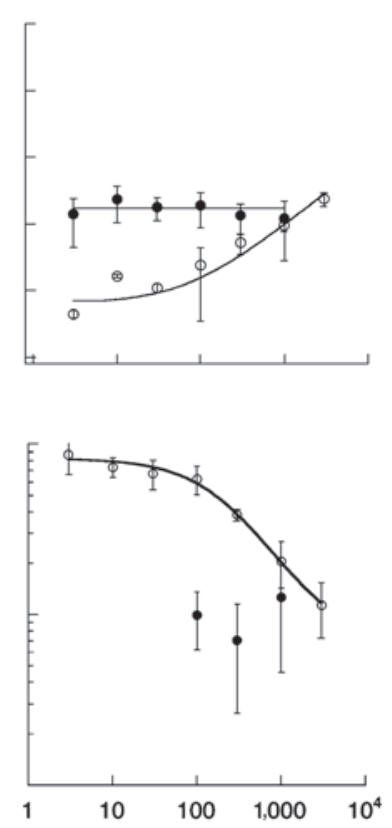

Fixed Interval Value (sec)

Figure 1. Initial pause durations (top panel) and run rates (bottom panel) as a function of the fixed-interval (FI) schedules. First column: data from 2 pigeons in Zeiler (1999). Open symbols represent the performance under open economies, giving smaller amounts of grain per reinforcer and some postsession feeding. Closed symbols represent the performance under closed economies, with 24-h sessions and ad lib amounts of grain per reinforcer. The remaining columns show the data from Experiments 1 and 2. Open symbols represent the average performance from the first $\mathbf{2 5}$ cycles in the session, and closed symbols the average from the last $\mathbf{2 5}$ cycles. Data are averages over 4 (second column) or 6 (third column) pigeons. Error bars span the interquartile range. The curves are derived from Equation 5 (pauses) and Equations 3-4.1 (response rates), with the parameters listed in Table 2. Data for rates are reported only when at least 20 trials contained measurable rates. Given the very long pauses in Zeiler's (1999) closed economy and in our end-of-session conditions, most trials at the shorter FI values contained only a single response.

plete, their weights dropped to $80 \%$ ad lib. No extra-session feeding was given, in order to maintain the definition of closed economy for all the conditions.

Schedules of food delivery. All the subjects experienced an ascending series of FI schedules of $3,10,30,100,300,1,000$, and $3,000 \mathrm{sec}$, followed by a descending series. The first response after the programmed interval elapsed illuminated the food key. Each schedule was in effect for two sessions, an exposure found adequate in the analysis of ratio schedule performance in closed economies by Foster et al. (1997).

\section{Results and Discussion}

Data analyses in this and all the subsequent experiments were based on the second session of each schedule, averaged over ascending and descending conditions, with the first four reinforcers excluded from the analyses in order to minimize any carryover effects from the prior session. The main dependent variables were (1) the duration of the initial pause after reinforcement, (2) the running rate (the response rate after the pause ended), (3) the overall response rate, and (4) the demand (the number of reinforcers earned per session). The average differences in the pigeons' body weights between the start and the end of the session were $30,30,36,39,23,3$, and $-1 \mathrm{~g}$ for FIs $3,10, \ldots 3,000 \mathrm{sec}$. As was engineered, the pigeons gained more weight under the short FIs than under the long ones, since the former provided more opportunities to eat during the 10-h sessions. We hypothesize that hunger at the end of the session was negatively correlated with the amount consumed during the session. In conditions in which the subjects ended the experiment $30 \mathrm{~g}$ heavier than when they started it, they may have been less hungry by the close of the session than they were in conditions in which they gained little or no weight. We base this noncontroversial, yet not uncontested, hypothesis on the common observation that humans claim to be less hungry after they have eaten to repletion.

The second column in Figure 1 displays the average pause durations (top panel) and the average response rates after the pause (bottom panel). At the start of the session (open circles, first 25 reinforcement cycles), pause durations increased as a function of the FI length. By the end of the session (closed circles, last 25 cycles), average pause 
durations remained constant up to interval lengths of 100 and then fell to a lower level. This discrepancy is highlighted by extending the trendline of the first four points over the last two. There are more data points for the start of the session (first 25 cycles) than for the end of the session (last 25 cycles). This is because these were fewer than 50 cycles in a session for the largest FI values: Up through the FI 100 schedule, the pigeons averaged a relatively constant 230 cycles and, thereafter, took the maximums of 120,35 , and 12 for the largest intervals.

In this and subsequent experiments, our pigeons responded sooner than did Zeiler's (1999). At FI lengths above 100, there were insufficient opportunities for the animals to eat to satiation: At FIs of 300, 1,000, and $3,000 \mathrm{sec}$, the pigeons gained only $68 \%, 9 \%$, and $0 \%$ of what they averaged at the other FI values, and thus they remained in a deprived state through the session. We believe that this is why the pause durations at the close of the session were shorter under these conditions. Hunger, not economy (which was invariant), seems to have controlled the shape of the functions.

Average run rates at the start of the session (bottom panel, second column, open circles) decreased with interval value, in accord with traditional operant research and with Zeiler's (1999) data. No data are plotted when fewer than 20 trials were available for estimates of run rates. Because pause durations typically exceed schedule requirement by the end of the session for short intervals, the single response that produced reinforcement provides insufficient data from which to calculate running rates.

The pausing patterns observed were consistent with Zeiler's (1999) data for open and closed economies, shown at the top of the first column of Figure 1, and the rate data for his open economy (bottom panel, open circles). For the one condition (FI 1,000 sec) in which both studies report response rates from the closed economy, our subjects responded at higher rates - about 20 responses per minute, as compared with 2 responses per minute for Zeiler's (1999).

Figure 1 shows data from the open and close of our sessions. Behavior between these points is an orderly function of the number of feedings received, as is shown in Figure 2 and the top panel of Figure 3. In both figures, overall rates are plotted as a function of the number of cycle activations. Figure 2 shows that comparable data were obtained on the ascending and the descending series. An exception is seen in the higher response rates during the first bin at the longest intervals for the descending conditions. These subjects started the sessions with body weights close to $80 \%$ ad lib, whereas in the ascending series, they were closer to $85 \%$ ad lib. The pigeons did not complete more ratios for FI $300 \mathrm{sec}$ in the descending condition, when they were lighter, than in the ascending condition. We believe that this is because their crop capacity places an upper limit on how much they can consume (Bizo et al., 1998). The top panel in Figure 3 shows satiation curves as a function of the number of feeding cycles, with FI value as a parameter. The curves are from a model

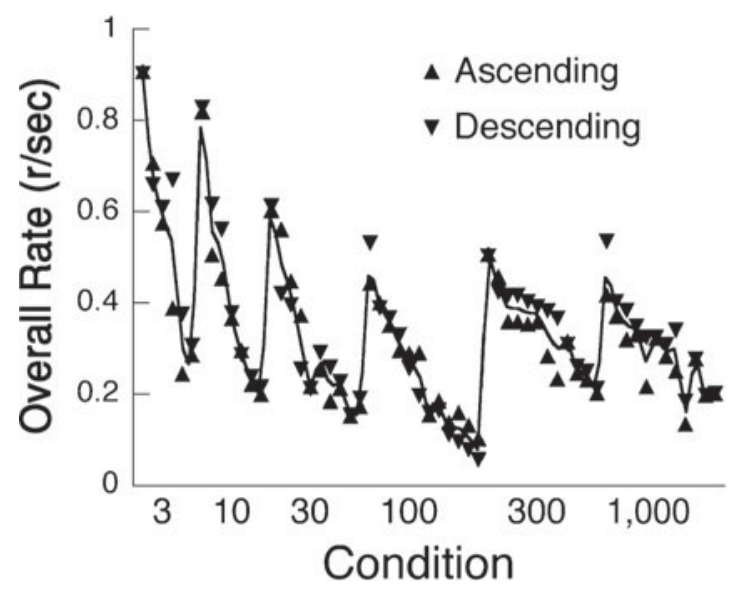

Figure 2. Average response rates over pigeons from ascending (up arrow) and descending (down arrow) conditions in Experiment 1 , in blocks of trials. The lines connect the average of ascending and descending blocks. The first six pairs of points represent the data from the fixed-interval (FI) 3-sec condition, the next set from the FI 10-sec condition, and so on.

of satiation (Killeen, 1995) described below. The results of Experiment 1 showed that it is possible to produce both open and closed economy patterns of pausing in a single session with invariant schedules of reinforcement, although our subjects' pauses were briefer than Zeiler's (1999). We did not replicate the pattern of run rates for closed economies.

\section{EXPERIMENT 2}

The purpose of Experiment 2 was to move the design toward that typical of closed economies by increasing the number of feedings per reinforcement cycle. If satiation is the causal factor in the rate decreases seen in the top panel of Figure 3, the decreases should be even steeper. Conversely, if failure to satiate at FI 300 and 1,000 sec was the cause of the briefer pauses seen in the top panel of Figure 1, in this experiment these points should move up toward the line.

\section{Method}

Subjects. Six pigeons (Columba livia), different from those used in Experiment 1, served as subjects. The birds started sessions at $85 \%$ of their free-feeding body weight, for which it was again necessary to conduct sessions on alternate days. No supplemental feeding was provided. All the pigeons were housed in individual cages, with water and grit freely available.

Apparatus and Procedure. The equipment and general procedure were the same as those in Experiment 1. The pigeons experienced an ascending series of FI schedules (the same values as those in Experiment 1), but instead of two hoppers per feeding cycle, as in Experiment 1, they could obtain four hoppers per cycle upon completion of the schedule requirement.

\section{Results and Discussion}

Weight gains during the session averaged 55, 34, 57, $37,36,12$, and $4 \mathrm{~g}$ for FIs 3, 10, 30, 100, 300, 1,000, and 3,000 sec. The third column in Figure 1 illustrates 


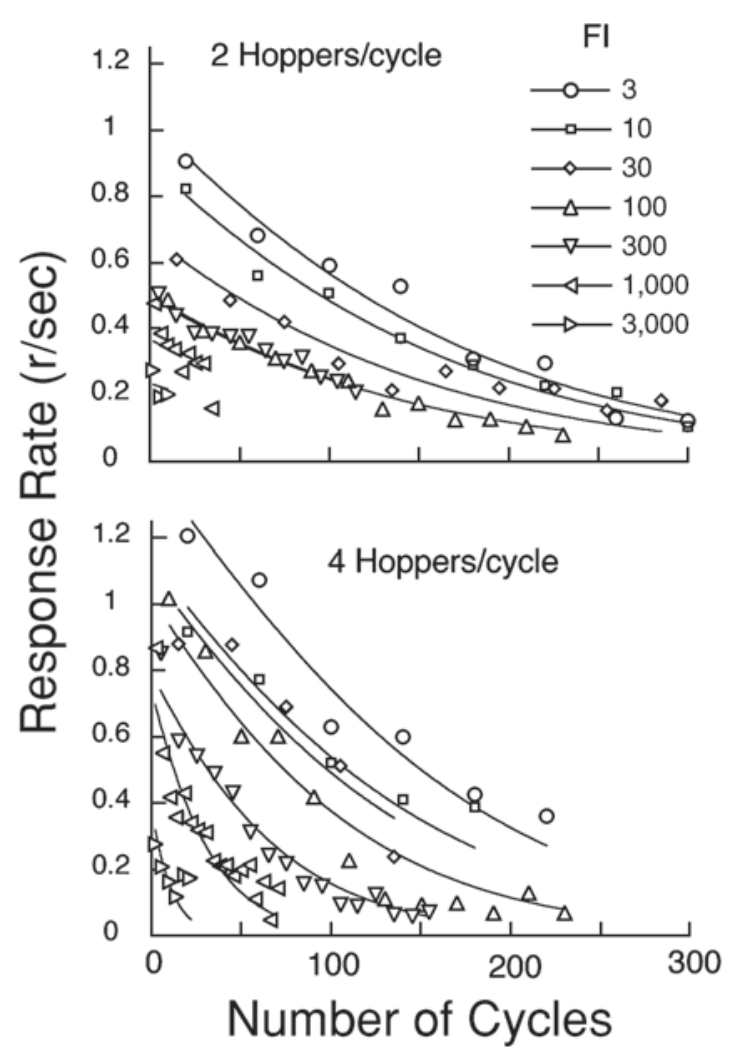

Figure 3. Satiation curves for pigeons receiving two hoppers/ cycle (Experiment 1) or four hoppers/cycle (Experiment 2). The data are overall response rates from successive blocks of cycles. The curves are from Equation 2, with hunger (and thus $a$ ) assumed to decrease exponentially as a function of the number of hoppers. The $y$-intercept of these curves increases with the rate of reinforcement (compare curves within panels) and magnitude of reinforcement (compare curves across panels), reflecting the quantitative law of effect typical of open economies.

the average pause durations (top panel) and the average response rates after the pause (bottom panel) for the FI schedules in the four hoppers/cycle condition. At the start of the sessions (open circles, first 25 reinforcers), pause durations increased as a function of the FI schedule. At the end of the sessions (closed circles, last 25 reinforcers), pause durations remained nearly constant, except at 300 and $1,000 \mathrm{sec}$, where they decreased. Weight gains for FI 1,000 and 3,000 sec were $27 \%$ and $9 \%$ of the average value under the other FI schedules. At the longest FIs, there were fewer trials separating the start and end of the session, and there was also more time for the pigeons to metabolize the food that they did receive.

The patterns observed were consistent with Zeiler's (1999) pause data for open and closed economies (see the first column in Figure 1), and rate data for his open economy (bottom panel, open circles). Zeiler (1999) did not report run rates for the small FI values in the closed economy. In our experiment, the average run rates were higher than Zeiler's (1999). Why did our response rate pattern not emulate Zeiler's (1999)? For Zeiler's (1999) subjects, meal size presumably increased regularly with interval value, since the pigeons presumably came to the meals hungrier at the longer intervals and would naturally then eat more. The increasing meal sizes could generate greater motivation at the longer ratios. Our subjects experienced similar intermeal intervals, but not the opportunity to replete given to Zeiler's (1999) pigeons. Therefore, they may have been generally more motivated, as is suggested by the higher running rates at 300- and 1,000-sec intervals and by the briefer pausing. But they did not enjoy correlated increases in reinforcer amount for the larger intervals.

A steeper decrease in within-session rates was observed during the four-hopper condition than in the two-hopper condition (compare the two panels in Figure 3). Figure 4 shows the response rates in successive blocks of reinforcement for the pigeons in the four hoppers/cycle condition plotted against those in the two hoppers/cycle condition. Rates above the diagonal are from the earlier parts of the sessions and show the faster responding for the larger reinforcers typical of open economies; rates below the diagonal show faster responding for smaller reinforcers, typical of closed economies and the ends of our experimental sessions, where satiation may be the controlling factor. With four hoppers/cycle, the pigeons started responding more quickly for the larger magnitude of reinforcement. Because they were receiving twice as much food per cycle and gaining much more weight per session, it may be hypothesized that they were becoming satiated, or if not that, perhaps habituating to the food; if not that, perhaps they were undergoing other systemic changes that were highly correlated with the amount of food they were consuming. Alternatively, they were moving from the control of an open economy to a de facto (i.e., subjectively) closed economy - even though the contingencies did not change - and their response rates were coming under control of these apparently altered economic circumstances. If any of the former, these results are consistent with the motivation hypothesis described below, which predicts greater incentive value for four versus two feedings/cycle, but greater repletion from it as well and, thus, a steeper decrease in response rate within the session. If the latter, anything could follow.

\section{EXPERIMENT 3}

To complete our exploration of the relation of motivation and economy, Experiment 3 employed FR schedules of reinforcement, replicating Zeiler's (1999) values.

\section{Method}

Subjects. The same pigeons as those used in Experiment 1 served as subjects. To maintain their body weight at $85 \%$ at the start of the session, it was necessary to conduct sessions on alternate days. No supplemental feeding was provided. All the pigeons were housed in individual cages, with water and grit freely available.

Apparatus and Procedure. The apparatus was the same as that used in the previous experiments. Pigeons experienced an ascending series of FR schedules of 4, 10, 26, 64, 160, 400, and 1,000. Comple- 


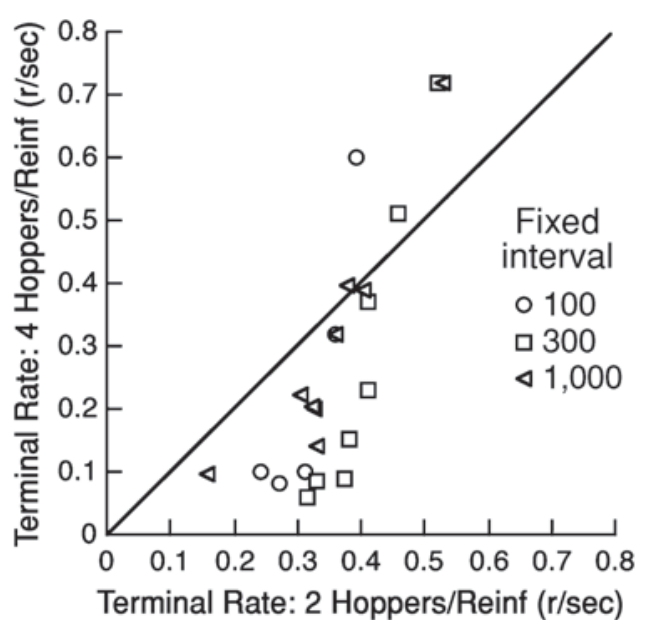

Figure 4. Terminal (running) rates in successive blocks of reinforcement for the pigeons in the four hoppers/cycle condition are plotted against those in the two hoppers/cycle condition. The blocks comprised 10 cycles for the FI 100 condition, 5 for FI 300, and 4 for FI 1,000. Rates above the diagonal issue from the start of the session and reflect faster responding in the four hoppers/ cycle condition; rates below the diagonal are from the end of the session and reflect slower responding in the four hoppers/cycle condition.

tion of the response requirement resulted in illumination of the right food key, after which the pigeons received two hoppers per cycle.

\section{Results and Discussion}

Weight gains during the session averaged 27, 34, 34, $47,15,6$, and $-2 \mathrm{~g}$ for FRs $4,10,26,64,160,400$, and 1,000 . Figure 5 illustrates the pause durations (top panel) and the response rates after the pause (bottom panel) for the FR schedules in Zeiler's (1999) experiment (left panels) and in Experiment 3 (right panels). At the start of the session, pause durations increased as a function of the FR schedule (open circles, first 25 reinforcers). By the close of the sessions (closed circles, last 25 reinforcers), pause durations remained constant over FR values. These patterns were consistent with Zeiler's (1999) pause data for open and closed economies, although the pause durations were generally lower for our end-of-session data.

FR run rates from the close of sessions did not resemble the pattern found by Zeiler (1999) but, rather, were almost identical to those from the start of the session. To test whether this might be due to an insufficient number of training sessions, at the end of this experiment, the pigeons were returned to FR 26 and were held there for 25 sessions. Pause lengths increased slightly, but response rates did not change significantly. This is the main qualitative difference we have found between our results and Zeiler's (1999).

\section{GENERAL DISCUSSION}

The present findings support the hypothesis that differences in motivation may explain some of the behavioral differences observed in open and closed economies. Pausing at the open of the session (when the subjects were hungry) resembled behavior in Zeiler's (1999) open economy, and behavior at the close of the session (when the subjects were less hungry) resembled that in Zeiler's (1999) closed economy. Running rates from the start of the session in our study replicated the standard open economy pattern, even though the paradigm in our experiments was closed. Response rates from the end of the sessions were generally higher than those Zeiler (1999) recorded from his closed economies, but sessions were not long enough (they were only $10 \mathrm{~h}$ long, rather than 24) to permit comparison over the largest intervals.

Responding decreased more quickly within sessions under the four-hoppers condition than under the two-hoppers condition (Figure 3). Motivational differences are clearly present and provide a privileged account of the different effects of open and closed economies. It is a privileged account because it uses an observed fact - changes in behavior consistent with changes in motivation - to account for other observed differences in response patterns, rather than positing a difference in elasticity or other economic construct as the causal factor.

There are additional reasons of parsimony to seek a general theory to account for behavior in both open and closed economies: Without such a general theory, two separate accounts are required, one for open economies and one for closed economies. Zeiler (1999, p. 171) called those two accounts different survival strategies, possibly strategies of weight conservation in closed economies and energy conservation in open economies. Collier called the two accounts economic versus physiological. With a general theory, one account may suffice. The price for generality - for asking a single theory to accommodate two domains of data - is to permit parameters to change between the domains. Two accounts, each with their own parameters, can be no more parsimonious. Furthermore, with two accounts, each requires a switch parameter to indicate when to engage the other account. In place of two accounts, a single theory in which motivation plays a crucial role will be offered below.

\section{An Economic Model}

Economics can point to the radically different operating characteristics of animals in open and closed procedures, such as those shown in the left column of Figure 1, and correctly claim that the different experimental procedures brought about different patterns of responding. It cannot explain the differences and, certainly, cannot predict their similarity to the data in the remaining columns. There are concepts in economics that can be brought to bear. Decreasing marginal utility of goods means that four hopper presentations will be less than twice as valuable as two hopper presentations. Utility can decrease for a variety of reasons. It can happen when animals satiate (two desserts are less than twice as valuable as one). It can happen if response rate is near its ceiling (Bizo \& Killeen, 1997). It can happen because the third and fourth reinforcers 

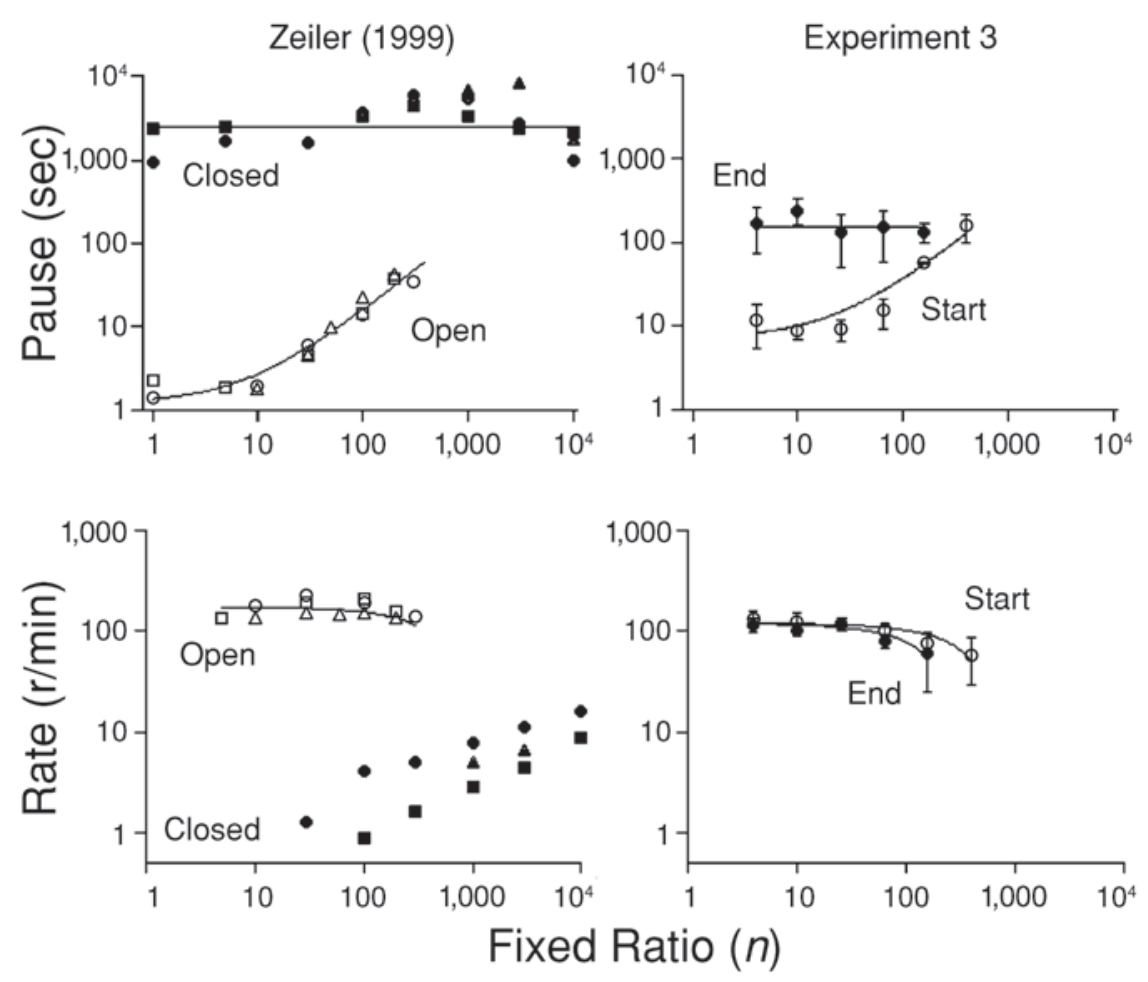

Figure 5. Initial pause duration (top row) and run rate (bottom row) as a function of the fixed-ratio (FR) schedules for Zeiler (1999; left column) and Experiment 3 (right column). Open circles represent the average of the first 25 reinforcer cycles for the FR in Experiment 3; closed circles represent the average of the last 25 cycles. The curves assume pause to be a linear function of ratio value. Response rates are from Equations 3 and 4.1, with the parameters in Table 1.

(or the third and fourth seconds of the same reinforcing event) are more remote from the target response than are the first and second events (or seconds; Killeen, 1985). It can also happen because extended reinforcement epochs block the reinforcement of responses by the subsequent reinforcers (Bizo, Kettle, \& Killeen, 2001). These are behavioral mechanisms that can be tested with behavioral arrangements. Decreasing marginal utility labels a result, inviting an experimental analysis to clarify the mechanism (Killeen, 2001).

\section{A Behavioral Model}

A general theory of potential use is the mathematical principles of reinforcement (MPR; Killeen, 1994). According to MPR, response rates are determined by three factors: (1) arousal, (2) coupling between responding and incentives, and (3) response constraints. The first principle states that reinforcers excite behavior, driving arousal level $(A)$ proportional to the rate of reinforcement $(r)$ :

$$
A=a r .
$$

The second principle determines how particular responses are coupled to, or associated with, reinforcers: Reinforcers strengthen responses closest in time to the reinforcer. The third principle reflects the increasing dif- ficulty of responding at higher rates, given the physical capabilities of the organism. These factors combine in a general rate equation (Killeen \& Sitomer, 2003):

$$
b=\frac{C a r}{\delta a r+1},
$$

where $b$ is the rate of responding, $C$ is coupling (the degree to which reinforcement is focused on the target response), $a$ is specific activation (the number of responses evoked by an incentive), $r$ is the rate of reinforcement, and $\delta$ is the time required to make a response. Specific activation, $a$, was a key variable in the present experiments: The product of $a$ and $r$ determines the organism's arousal level. When coupled to operant responses, arousal level modulates response rates.

Killeen (1995) applied this model to experimental economies, arguing that economy-dependent effects in rate functions were caused by changes in arousal. He assumed that the increase in response rates with schedule size sometimes found in closed economies was due to increases in hunger that occurred with long interfood intervals. Under those assumptions, he modeled the open/ closed economy results of Hursh (1980) and generated representative demand functions. Zeiler (1999) agreed that demotivation due to satiation was a plausible assump- 
tion that fit the closed economy data, but for MPR "to work for open economies, hunger must decrease with longer interfood intervals, which seems unlikely" (p. 182). This interpretation of MPR is incorrect. Arousal level is the controlling variable. Three factors govern arousal level (see Equation 1): It increases with rate of reinforcement ( $r$ ) or amount of reinforcement (a factor in $a$ ); it decreases with satiation, another factor in $a$. There is a trade-off between $a$ and $r$ when rate of reinforcement is increased. With all other factors equal, response rates will increase with increases in specific activation $(a)$ or with increases in rate of reinforcement $(r)$. But increases in rate of reinforcement, especially in closed economies with large meals or long sessions, can satiate the animal, causing a decrease in $a$. A pellet given to a hungry rat will have a different effect on arousal $(A)$ than will the same pellet given to a satiated rat, because $a$ is smaller for a satiated rat (see Equation 1). In open economies, deprivation levels and, thus, $a$ are held relatively constant, and $r$ becomes the most important controlling variable. In closed economies, $a$ varies widely and is then the major controlling variable.

The behavioral approach combines a version of Herrnstein's quantitative law of effect (Equation 2; see de Villiers \& Herrnstein, 1976) with common sense about the effect of satiation on motivation. These opposing forces are differentially brought to bear in the two economies. (1) Traditional open economy procedures were designed so that satiation is not a major factor. The law of effect predicts that response rates will increase as a function of rate of reinforcement and, thus, will decrease with the interfood interval. This causes the negative slope in response rates shown by the open symbols in the bottom panels of Figure 1. (2) The dynamics of closed economies are strongly controlled by cycles of depletion and repletion. Deprivation causes response rates to increase as a function of the percentage of body weight lost (Collier \& Johnson, 1997); conversely, satiation causes response rates to decrease as a function of amount of food consumed (Figure 3; Bizo et al., 1998). Animals are able to consume food at a higher rate when the time between feedings is brief or the amount of food provided is large and, thus, can maintain their state closer to satiation. If they are satiated, they will not be motivated to respond for food. If they do not respond, they will not make contact with very short-programmed interfood intervals. This is seen in Zeiler's (1999) data, where, up to intervals of $1,000 \mathrm{sec}$, the pigeons' average pause was substantially longer than the minimal interfood interval. Above this floor of repletion, response rates must increase to maintain desired intake (filled symbols, bottom left panel of Figure 1). Hunger and satiety, not economic laws, drive these effects.

The behavioral approach predicts that during the course of long sessions involving large feedings, response rates will decrease in a continuous fashion as animals satiate, an inference supported by the present experiments (see Figure 3). The data from all the conditions look very similar when plotted in terms of the number of hopper activations.
When plotted in terms of number of cycles, however, the satiation curves decline more slowly in those conditions in which the animals received only two hoppers per cycle. This is shown in Figure 4. The curves through the data in Figure 3 are derived from MPR (Killeen, 1995), which incorporates the trade-off between activation and satiation. Hunger decreases as a function of the number of hopper activations (the parametric curves); the rate of decrease is a linear function of the interfood interval (the changes in slope for the parametric curves).

The behavioral approach may explain why response rates look different in these procedures. Figure 6 shows the overall response rates in rates in open and closed economies reported by Zeiler (1999). The decrease in response rates in the open economy is expected: Rate of responding is generally a positive function of rate of reinforcement (Lowe, 1979; Zeiler, 1979). This is the quantitative law of effect (de Villiers \& Herrnstein, 1976). The increase in response rates in the closed economy is consistent with animals being hungrier under leaner schedules. A simplified model based on MPR captures both of these effects. Substitute $r=1 /$ IFI in Equation 2 and rearrange to get the expected response rate:

$$
b=\frac{C}{\delta+\mathrm{IFI} / a}
$$

with

$$
a=v(m) h\left[d_{0}+(M-m / \mathrm{IFI}) t\right]
$$

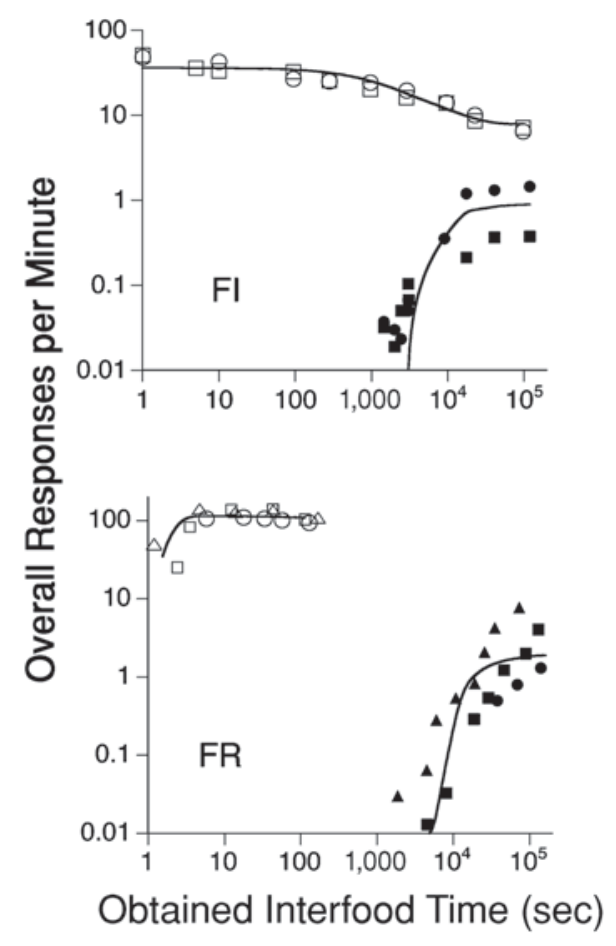

Figure 6. Overall response rates reported by Zeiler (1999) as a function of the obtained interfood intervals. The curves are given by Equations 3-5, with the parameters shown in Table 2. 
For parsimony, the parameter $C$ is held at 1 . IFI is the interval between opportunities to eat. The parameter $a$ is specific activation. It is a product of incentive value of the reinforcer, $v(m)$, and deprivation, the term in brackets. This term comprises initial deprivation level $\left(d_{0}\right)$ plus the difference between rates of output ( $M$, metabolic rate) and input (reinforcer size, $m$, per unit of time). These net rates are multiplied by the elapsing time to give a dynamic model of the changes in food motivation as a function of time. By what function $h[]$ is deprivation converted into hunger? Figure 3 showed exponential decreases in response rates as a function of number of feedings. For the more limited range of steady-state data shown in Figure 6, a simpler representation is possible if we assume a linear decrease, $k\left[d_{0}+(M-m / \mathrm{IFI}) t\right]$, as found by Aoyama $(1998,2000$; Aoyama \& McSweeney, 2001). For the static values in Figure 6, set $t$ equal to the average interfood interval, IFI. Then, Equation 4 becomes

$$
a=v(m) k\left[d_{0}+M \cdot \text { IFI }-m\right] .
$$

Finally, let the incentive value of the reinforcer $v^{\prime}(m)$ absorb the multiplicative constant $k$ of the hunger function, and set $d_{0}^{\prime}=d_{0}-m$. Then,

$$
a=v^{\prime}(m)\left[d_{0}^{\prime}+M \cdot \mathrm{IFI}\right] .
$$

A further simplification is possible if we take $15 \mathrm{~g}$ as the average amount of food that pigeons metabolize in $24 \mathrm{~h}$, which gives a value of $0.00017 \mathrm{~g} / \mathrm{sec}$ for $M$. This leaves three free parameters: $\delta$ (the time required for a response), $v^{\prime}(m)$ (proportional to the incentive value of the reinforcer), and $d_{0}^{\prime}$ (the initial deprivation minus the amount per feeding $m$ ). The critical parameter is $d_{0}^{\prime}$ : It should be large for animals in open economies and near zero or negative under closed economies. The curves in Figure 6 are the trace of this model for open and closed economies and demonstrate the radical changes in the shape of the response rate curves resulting from changes in the parameter $d_{0}^{\prime}$. The parameters are given in Table 2, where $d_{0}^{\prime}$ is higher under open economies.

The behavioral approach may explain why pausing looks so different in these two procedures. On typical FI schedules, animals may respond only when the probability of reinforcement exceeds some threshold. If the error in timing the interval is consistent with Weber's law (i.e., scalar timing), pause length should be a linear function of interval value. Data show that the point of inflection in FI scallops (the breakpoint; Hanson \& Killeen, 1981; Schneider, 1969 ) is proportional to FI value. Time to the first peck is also sometimes a linear function of the interreinforcer interval (Zeiler \& Powell, 1994), but sometimes, it is a power function of the interreinforcer interval (Hanson \& Killeen, 1981; Lowe, Harzem, \& Spencer, 1979). The lines through the pause durations in Figure 1 are linear functions of the FI value, consistent with the linear waiting time model (Higa, Moreno, \& Sparkman, 2002; Staddon, Chelaru, \& Higa, 2002; Wynne, Staddon, \& Delius, 1996):

$$
P=P_{0}+k\left[\mathrm{FI}-P_{0}\right]^{+},
$$

Table 1

Pause Parameters (Equation 5 for All Fixed Interval [FI] Schedules and the Linear Equation $P=P_{0}+k n$ for Fixed Ratio [FR] Schedules) and Rate Parameters

\begin{tabular}{|c|c|c|c|c|c|}
\hline \multirow[b]{2}{*}{ Experiment } & \multicolumn{2}{|c|}{ Pause Parameters } & \multicolumn{3}{|c|}{ Rate Parameters } \\
\hline & $P_{0}(\mathrm{sec})$ & $k$ & $\delta(\mathrm{sec})$ & $d_{0}^{\prime}(\mathrm{g})$ & $v^{\prime}(/ \mathrm{g})$ \\
\hline Zeiler FI open & 1 & 0.61 & 1.00 & 1.93 & 900 \\
\hline Zeiler FI closed & 1,200 & 0.05 & & & \\
\hline Exp. 1 open & 7 & 0.05 & 0.95 & 0.03 & 2,400 \\
\hline Exp. 1 close & 260 & & & & \\
\hline Exp. 2 open & 7 & 0.09 & 0.75 & 0.51 & 700 \\
\hline Exp. 2 close & 170 & & & & \\
\hline Exp. 3 open & 7 & 0.30 & 0.50 & 0.09 & 80 \\
\hline Exp. 3 close & 153 & & 0.50 & 0.04 & 80 \\
\hline Zeiler FR open & 1 & 0.15 & 0.35 & 0.20 & 60 \\
\hline Zeiler FR closed & 2,500 & & & & \\
\hline
\end{tabular}
(Equations 3 and 4.1) Used in Drawing the Functions Shown in Figures 1 and 5

where $P_{0}$ is the initial postprandial pause, $k$ is a constant of proportionality, and $\left[\mathrm{FI}-P_{0}\right]^{+}$is zero until the FI exceeds the pause and, thereafter, is the time left in the FI interval. The parameters of this function are shown in Table 1. This model suggests that part of the pause, $P_{0}$, may be under the control of hunger level and that, once that has risen past threshold, further pausing is proportional to the time remaining to reinforcement.

Why should the functions look so different under the two economic conditions? Perhaps because animals are not motivated to respond until their body weight falls below some criterion (see, e.g., Bolles, 1967; Killeen \& Reilly, 2001). Assume, for the sake of argument, that pigeons metabolize $15 \mathrm{~g}$ of grain per day and that they are motivated to respond when they have lost a quarter of a gram. It follows that they will pause, on the average, $24 \mathrm{~min}$, or 1,440 sec, after each feeding before engaging in behavior under the control of the schedule of reinforcement. If the pause duration is thereafter proportional to the FI value, the curve through the filled symbols in Zeiler's (1999) data (Figure 1) results. If pigeons are much hungrier, as is typically the case in open economies, the postprandial pause (Harzem \& Harzem, 1981; Harzem, Lowe, \& Spencer, 1978) will be minimal, and pausing will come more strongly under schedule control, as the curve through the open symbols shows. A simple, linear, singleprocess model with interpretable parameters thus accounts for pause behavior in both open and closed economies. Table 1 lists the parameters for these pause functions.

Table 2

Parameters of Equations 3 and 4.1 Used in Drawing the Functions Shown in Figure 6

\begin{tabular}{lccc}
\hline & \multicolumn{3}{c}{ Parameters } \\
\cline { 2 - 4 } Experiment & $\delta(\mathrm{sec})$ & $d_{0}^{\prime}(\mathrm{g})$ & $v^{\prime}(/ \mathrm{g})$ \\
\hline Zeiler FI open & 1.67 & 1.35 & 900 \\
Zeiler FI closed & 1.67 & -0.57 & 100 \\
Zeiler FR open & 0.53 & 4.94 & 900 \\
Zeiler FR closed & 0.53 & -1.55 & 200 \\
\hline
\end{tabular}


MPR has not yet been developed to predict run rates on FI schedules, but that is straightforward. Decompose the behavior into the pausing and running components and apply the model above (Equation 3 ) to the running component, subtracting the average pause duration from the FI value. The resulting fits are shown by the curves through the open symbols in Figure 1. Because pausing is generally proportional to IFI on FI schedules, an identical curve through the data may be derived by the model without the adjustment for pausing, simply by letting that constant of proportionality be absorbed into the other parameters. Ratio schedule performance may be predicted by the same equations (Figure 5). No attempt is made to fit Zeiler's (1999) data, because meal size presumably increased regularly with ratio value, since the pigeons experienced longer intervals between meals and, presumably, came to the meals hungrier at the longer intervals. This larger meal size would naturally generate greater incentive motivation $v^{\prime}(m)$ at the longer ratios. Meal sizes could be inferred from the assumption that the pigeons will defend a daily intake of $15-30 \mathrm{~g}$ and from the known relation between eating time, consumption rate, and incentive value (Killeen, 1985). However, eating rates are likely to decrease as the animals satiate (Belke \& Kwan, 2000); in the attempt to keep the modeling exercise simple, that is not assayed here.

There were many simplifications made in these models in order to keep their machinery transparent and the parameters minimal (Zeiler, 1996). Hunger levels may change as a convex, not linear, function of net deprivation; coupling (C) was assumed to be constant and maximal; a number of parameters were lumped into $v^{\prime}, d_{0}$, and $\delta$. Interfood interval grows as a convex, not linear, function of ratio value. Zeiler (1999) increased meal size with schedule value for long schedules in his open economy, a procedural nuance not included in the model. These are not perfected models but, rather, proofs of concept. Least satisfying is the use of separate models for pauses and rates; a general model should integrate them. Refinements would improve the fit and broaden the range of the models, but at the cost of an increased number of functioning parameters.

Collier and associates (Collier et al., 1986; Collier \& Rovee-Collier, 1981) have argued that paradigms that more closely approximate the natural feeding regimen of animals offer a more valid method for the studying of behavior. In most cases these procedures permit the animal to terminate meals at will, rather than receive fixed-quantity reinforcers. Collier found that many data are parsimoniously organized by the construct unit price - amount of food divided by schedule requirements (Collier, Johnson, \& Mathis, 2002). In the realm in which depletion and repletion are the controlling forces, this makes sense. Collier (1986) has couched his analyses as a dialogue between two systems - one physiological, the other economic: "The House Economist attempts to anticipate requirements, and the Resident Physiologist attempts to buffer the fluctuations caused by the variable market and the House Economist's decisions" (p. 9). He gave as an

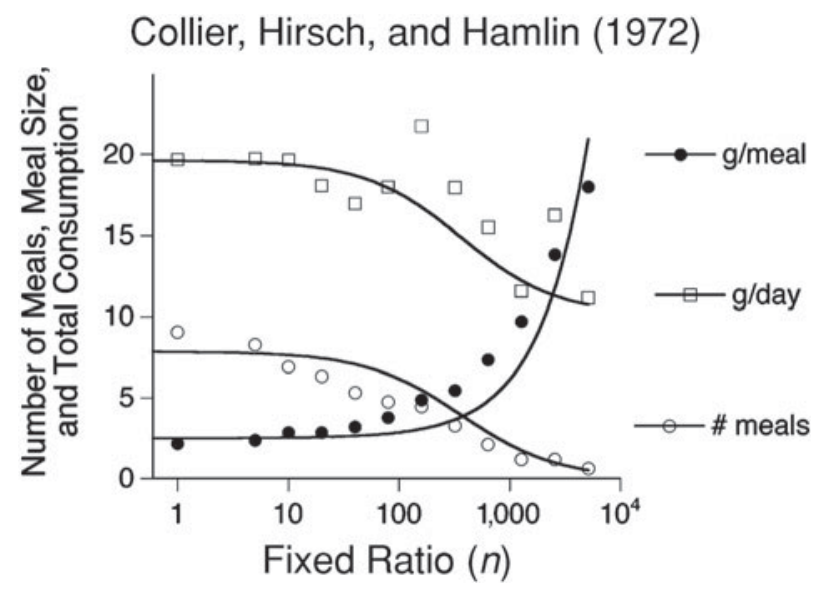

Figure 7. Median data from 3 rats as a function of ratio size in a closed economy, extracted from Collier (1986). The ascending curve assumes that meal size $(M S)$ is a linear function of time since the last meal (measured as the fixed-ratio value) $M S=d_{0}+$ $m n$ (Equation 5), with $d_{0}=3 \mathrm{~g}$ and $m=0.0035 \mathrm{~g}$. The number of meals (circles) is found by dividing the number of seconds in $24 \mathrm{~h}$ by the expected interfood interval: IFI $=P_{0}+k n$, with $P_{0}=$ 11,000 sec and $k=30$ sec.

example the data shown in Figure 7, where rats in a closed economy adjusted the meal size as a function of the cost to maintain a relatively constant intake up to ratios of 160 . The top curve, the predicted consumption, is the product of the other two; up to ratios of 100, it is constant: Animals successfully defend their intake, and demand is inelastic. Thereafter, they cannot consume enough during a meal to keep up with depletion while earning the next meal. This result "should probably be called a 'Collier function' because it has been found in so many species and occurs reliably at the level of individual animals" (Rashotte, 2002, p. 149).

There is a kind of duality in open and closed economies, but both aspects are physiological. Open economies open the feedback loop between behavior and complete satisfaction of needs, so that motivation is relatively constant. Closed economies close that loop, so that motivations fluctuate. Open economies are useful for studying control by discriminative stimuli and contingencies of reinforcement; closed economies are useful for studying foraging systems under the control of fluctuating motivation. Our goal is to integrate these. The curves shown in Figure 7 do not require subjects to make economic calculations to anticipate the next ratio - no call for a house economist. They require the rats to be hungrier after completing long ratios and to eat until that hunger is satisfied. They then pause several hours before they begin responding for a length of time proportional to the ratio requirement. Perhaps satiation/repletion is a more biologically plausible explanation than economic constraint. It at least provides a mechanism. But then again, perhaps the economic and motivational explanations are but alternate versions of the same reality. 
Closed economies are not necessarily more natural than open economies, nor do they better approximate natural foraging regimens. Some animals, such as large predators, may sometimes be able to acquire meals sufficient to satiate them, but many must make do with small meals acquired through continual effort. Nonetheless, Collier's (1986) and Zeiler's (1999) central point - that open economies are but one arrangement of contingencies and that other arrangements will bring about different patterns of behavior-is inarguable.

Skinner chose the reflex as his unit of analysis, and rate became his measure of response strength. Feeding (and drinking) became the subject of his analysis, and reinforcement the mechanism. Stemming from Richter's account of feeding (and drinking, running, climbing, etc.) we have used the bout as the unit of analysis. Bout measurement necessarily requires a closed economy. The functions we have found using bouts as the unit of analysis using the typical operant experimental variables are very different from what you get using the response as the unit of analysis. (Collier, personal communication, 2003)

We agree with these observations and echo Zeiler's (1999) conclusion: "The present results complement many others in emphasizing that any general theory of operant behavior must deal with how feeding economies influence behavior" (p. 185).

\section{REFERENCES}

Aoyama, K. (1998). Within-session response rate in rats decreases as a function of amount eaten. Physiology \& Behavior, 64, 765-769.

Aoyama, K. (2000). Effects of hunger state on within-session response decreases under CRF schedule. Learning \& Motivation, 31, 1-20.

Aoyama, K., \& McSweeney, F. K. (2001). Habituation may contribute to within-session decreases in responding under high-rate schedules of reinforcement. Animal Learning \& Behavior, 29, 79-91.

BELKE, T. W., \& KwAN, T. Y. (2000). The effect of changes in availability on food selection at different levels of deprivation. Psychological Record, 50, 529-541.

Bernstein, D. J., \& EbBesen, E. B. (1978). Reinforcement and substitution in humans: A multiple-response analysis. Journal of the Experimental Analysis of Behavior, 30, 243-253.

Bizo, L. A., Bogdanov, S. V., \& Killeen, P. R. (1998). Satiation causes within-session decreases in instrumental responding. Journal of Experimental Psychology: Animal Behavior Processes, 24, 439-452.

Bizo, L. A., Kettle, L. C., \& Killeen, P. R. (2001). Rats don't always respond faster for more food: The paradoxical incentive effect. Animal Learning \& Behavior, 29, 66-78.

Bizo, L. A., \& KilleEn, P. R. (1997). Models of ratio schedule performance. Journal of Experimental Psychology: Animal Behavior Processes, 23, 351-367.

Bolles, R. C. (1967). Theory of motivation. New York: Harper \& Row.

Collier, G. H. (1986). The dialogue between the House Economist and the Resident Physiologist. Nutrition \& Behavior, 3, 9-26.

Collier, G. H., Hirsch, E., \& Hamlin, P. H. (1972). The ecological determinants of reinforcement in the rat. Physiology \& Behavior, 9, 705-716.

Collier, G. [H.], \& Johnson, D. F. (1990). The time window of feeding. Physiology \& Behavior, 48, 771-777.

Collier, G. [H.], \& Johnson, D. F. (1997). Who is in charge? Animal vs. experimenter control. Appetite, 29, 159-180.

Collier, G. H., Johnson, D. F., Hill, W. L., \& Kaufman, L. W. (1986). The economics of the law of effect. Journal of the Experimental Analysis of Behavior, 46, 113-136.

Collier, G. H., Johnson, D. F., \& Mathis, C. (2002). The currency of procurement cost. Journal of the Experimental Analysis of Behavior, 78, 31-61.

Collier, G. H., \& Rovee-Collier, C. K. (1981). A comparative analysis of optimal foraging behavior: Laboratory simulations. In A. Kamil \& T. D. Sargent (Eds.), Foraging behavior: Ecological, ethological, and psychological approaches (pp. 39-76). New York: Garland.

de Villiers, P. A., \& Herrnstein, R. J. (1976). Toward a law of response strength. Psychological Bulletin, 83, 1131-1153.

Foster, T. M., Blackman, K. A., \& Temple, W. (1997). Open versus closed economies: Performance of domestic hens under fixed-ratio schedules. Journal of the Experimental Analysis of Behavior, 67, 6789.

Hall, G. A., \& Lattal, K. A. (1990). Variable-interval schedule performance in open and closed economies. Journal of the Experimental Analysis of Behavior, 54, 13-22.

Hanson, S. J., \& KilleEn, P. R. (1981). Measurement and modeling of behavior under fixed-interval schedules of reinforcement. Journal of Experimental Psychology: Animal Behavior Processes, 7, 129-139.

Harzem, P., \& Harzem, A. (1981). Discrimination, inhibition, and simultaneous association of stimulus properties: A theoretical analysis of reinforcement. In P. Harzem \& M. D. Zeiler (Eds.), Advances in analysis of behaviour: Vol. 2. Predictability, correlation, and contiguity (pp. 81-124). Chichester, U.K.: Wiley.

Harzem, P., Lowe, C. F., \& Spencer, P. T. (1978). Temporal control of behavior: Schedule interactions. Journal of the Experimental Analysis of Behavior, 30, 255-270

Higa, J. J., MoReno, S., \& Sparkman, N. (2002). Interval timing in rats: Tracking unsignaled changes in the fixed interval schedule requirement. Behavioural Processes, 58, 167-176.

Hopkins, A. (1966). The pattern of gastric emptying: A new view of old results. Journal of Physiology, 182, 144-150.

HuRsh, S. R. (1978). The economics of daily consumption controlling food- and water-reinforced responding. Journal of the Experimental Analysis of Behavior, 29, 475-491.

HURSH, S. R. (1980). Economic concepts for the analysis of behavior Journal of the Experimental Analysis of Behavior, 34, 219-238.

HuRsh, S. R. (1984). Behavioral economics. Journal of the Experimental Analysis of Behavior, 42, 435-452.

Johnson, D. F., \& Collier, G. [H.] (1999). Prey size and prey density affect meal patterns of rats in depleting and nondepleting patches. Animal Behaviour, 58, 409-419.

KILLEEN, P. R. (1985). Incentive theory: IV. Magnitude of reward. Journal of the Experimental Analysis of Behavior, 43, 407-417.

KilleEN, P. R. (1994). Mathematical principles of reinforcement. Behavioral \& Brain Sciences, 17, 105-131.

Killeen, P. R. (1995). Economics, ecologics, and mechanics: The dynamics of responding under conditions of varying motivation. Journal of the Experimental Analysis of Behavior, 64, 405-431.

KilleEn, P. R. (2001). The four causes of behavior. Current Directions in Psychological Science, 10, 136-140.

Killeen, P. R., \& ReIlly, M. P. (2001). No thanks, I'm good. Any more and I'll be sick: Comment on Lynch and Carroll (2001). Experimental \& Clinical Psychopharmacology, 9, 144-147.

Killeen, P. R., \& Sitomer, M. T. (2003). MPR. Behavioural Processes, 62, 49-64.

LeA, S. E. G. (1978). The psychology and economics of demand. Psychological Bulletin, 85, 441-466.

Logan, F. A. (1964). The free behavior situation. In D. Levine (Ed.), Nebraska Symposium on Motivation (Vol. 12, pp. 99-128). Lincoln: University of Nebraska Press.

Lowe, C. F. (1979). Determinants of human operant behavior. In M. D. Zeiler \& P. Harzem (Eds.), Advances in analysis of behaviour: Vol. 1. Reinforcement and the organization of behaviour (pp. 159-192). Chichester, U.K.: Wiley.

Lowe, C. F., Harzem, P., \& Spencer, P. T. (1979). Temporal control of behavior and the power law. Journal of the Experimental Analysis of Behavior, 31, 333-343.

McSweEney, F. K., Hinson, J. M., \& CANnON, C. B. (1996). Sensitizationhabituation may occur during operant conditioning. Psychological Bulletin, 120, 256-271.

McSweeney, F. K., Roll, J. M., \& Weatherly, J. N. (1994). Within- 
session changes in responding during several simple schedules. Journal of the Experimental Analysis of Behavior, 62, 109-132.

McSweeney, F. K., \& Swindell, S. (1999). General-process theories of motivation revisited: The role of habituation. Psychological Bulletin, 125, 437-457.

Rashotte, M. E. (2002). Closed-economy energetics. Appetite, 38, 149154.

Roll, J. M., McSweeney, F. K., Johnson, K. S., \& Weatherly, J. N. (1995). Satiety contributes little to within-session decreases in responding. Learning \& Motivation, 26, 323-341.

SCHNEIDER, B. (1969). A two state analysis of fixed-interval responding in the pigeon. Journal of the Experimental Analysis of Behavior, 12, 677-687.

Staddon, J. E. R., Chelaru, I. M., \& Higa, J. J. (2002). Habituation, memory and the brain: The dynamics of interval timing. Behavioural Processes, 57, 71-88.

Timberlake, W. (1984). A temporal limit of the effect of future food on current performance in an analogue of foraging and welfare. Journal of the Experimental Analysis of Behavior, 41, 117-124.

Timberlake, W., Gawley, D. J., \& LuCas, G. A. (1987). Time horizons in rats foraging for food in temporally separated patches. Journal of Experimental Psychology: Animal Behavior Processes, 13, 302-309.

Wynne, C. D. L., Staddon, J. E. R., \& Delius, J. D. (1996). Dynamics of waiting in pigeons. Journal of the Experimental Analysis of Behavior, 65, 603-618.

ZeILer, M. D. (1979). Output dynamics. In M. D. Zeiler \& P. Harzem (Eds.), Advances in analysis of behaviour: Vol. 1. Reinforcement and the organization of behaviour (pp. 79-115). Chichester, U.K.: Wiley.

ZEILER, M. D. (1991). Ecological influences on timing. Journal of Experimental Psychology: Animal Behavior Processes, 17, 13-25.

ZEILER, M. D. (1996). What behavers do. Behavioral \& Brain Sciences, 19, 549-550.

ZeILER, M. D. (1999). Reversed schedule effects in closed and open economies. Journal of the Experimental Analysis of Behavior, 71, 171-186.

Zeiler, M. D., \& Powell, D. G. (1994). Temporal control in fixedinterval schedules. Journal of the Experimental Analysis of Behavior, 61, 1-9.

(Manuscript received July 21, 2004;

revision accepted for publication February 22, 2005.) 